\title{
Experimental Analysis of Asbestos Fibre Reinforced Concrete Composite
}

\author{
Rahul Chaudhary, Shahbaz Ahamad, Varshney Kumar Patel, Nabiullah Khan \\ Department of Civil Engineering, Suyash Institute of Information Technology Gorakhpur, Uttar Pradesh, India
}

\begin{abstract}
All countries are focusing on sustainable technology that can be economical and adopted for the use of concrete in a better way. Concrete is most widely used construction material and it possesses very low tensile strength, low shear strength and brittle characteristics. In order to improve these properties a relatively new construction material developed through extensive research and development work called Fibre Reinforced Concrete (FRC). An attempt has been made to analyze the effect of addition of asbestos fibre in ordinary portland cement concrete at their optimum proportions. To determine the properties concrete compressive strength and flexural strength test were performed at different test age like 7, 14 and 28 days. $M 30$ grade concrete was designed as per IS 10262-2009. The additions of fibre were varying from $0.33 \%, 0.66 \%, 1.0 \%$, $1.33 \%, 1.66 \%$ and $2.0 \%$ by volume of concrete for AFRC. The maximum compressive strength of AFRC obtained at $0.33 \%$ addition of fibre. Test results shows that the compressive strength of AFRC marginally improved, but there is a significant improvement in the flexural strength.
\end{abstract}

Keywords: Asbestos Fibre Reinforced Concrete, Fiber Reinforcement, Asbestos Fiber reinforcement, Reinforced Fiber Concrete.

\section{Introduction}

Plain concrete, regularly known as concrete, is a cozy blend of binding material, fine aggregate, coarse aggregate and water. This can be effectively formed to sought shape and size before it looses pliancy and solidifies. Plain concrete is strong in compression yet exceptionally feeble in tension. The tensile property is presented in concrete by drafting diverse materials and this endeavor has offered ascend to RCC, RBC, PSC, FRC, cell cement and Ferro concrete.

\subsection{Reinforced Cement Concrete (R.C.C.)}

Concrete has been great in opposing pressure yet is extremely feeble in opposing tension. Subsequent support is given in the Concrete wherever tensile stress is expected. The best fortification is steel, since rigidity of steel is very high and the bond amongst the steel and concrete is great. As the elastic modulus of steel is high, for a similar augmentation the compel opposed by steel is high contrasted with concrete. However, in ductile zone, hair cracks in concrete are unavoidable.

\subsection{Reinforced Brick Concrete (RBC)}

It is the blend of support, brick and concrete. It is a verifiable truth that brick is exceptionally frail in pressure. Thus, in the sections, lintels and pillars the concrete in the segment underneath the neutral axis don't take an interest in opposing the heap. It goes about as a filler material as it were. Henceforth to accomplish economy the concrete in tensile zone might be supplanted by bricks or tiles. Thick concrete mortar is utilized to implant the fortification. The fortification might be steel bars, extended work and so on.

\subsection{Prestressed Concrete (PSC)}

Strength of concrete in tension is low and thus it is disregarded in R.C.C. design. Concrete in strain is going about as a cover to steel and keeping steel at sought separation. In this way in R.C.C. parcel of concrete is not appropriately used. Prestressing the concrete is one of the technique for using whole concrete. The guideline of prestressed concrete is to present computed compressive stresses in the zones wherever pliable burdens are normal in the concrete basic components. At the point when such basic component is utilized burdens created because of stacking needs to first invalidate these compressive worries before presenting tractable worry in concrete. Along these lines in prestressed concrete whole concrete is used to oppose the heap. Another vital preferred standpoint of PSC is hair cracks are maintained a strategic distance from in the concrete and consequently durability is high.

\subsection{Fibre-Reinforced Concrete (FRC)}

Plain concrete has inadequacies like low tensile strength, restricted pliability and low imperviousness to breaking. The splits grow even before stacking. In the wake of stacking miniaturized scale splits broaden and 
engender, presenting concrete to air activities. On the off chance that firmly divided and consistently dispered filaments are given while blending concrete, breaks are captured and static and dynamic properties are made strides. Fiber strengthened concrete can be characterized as a composite material of concrete or mortar with broken and consistently conveyed strands. Usually utilized strands are of steel, nylon, asbestos, coir, glass, carbon and polypropylene. The length to parallel measurement of filaments range from 30 to 150 . The breadth of strands fluctuate from 0.25 to $0.75 \mathrm{~mm}$. Fiber fortified concrete is having better rigidity, pliability and imperviousness to breaking

\subsection{Cellular Concrete}

It is a light weight concrete formed by hosting large voids in the concrete or mortar. Its density varies from 3 $\mathrm{kN} / \mathrm{m} 3$ to $8 \mathrm{kN} / \mathrm{m} 3$ whereas plain concrete density is $24 \mathrm{kN} / \mathrm{m} 3$. It is also known as aerated, foamed or gas concrete.

\subsection{Ferro-Cement}

The term ferro-cement indicates the combination of ferrous product with cement. Normally this combination is in the form of steel wires meshes fixed in a portland cement mortar. Wire mesh is usually of 0.8 to $1.00 \mathrm{~m}$ diameter steel wires at $5 \mathrm{~mm}$ to $50 \mathrm{~mm}$ space and the cement mortar is of cement sand relation of 1:2 or 1:3. $6 \mathrm{~mm}$ diameter bars are also used at large spacing, rather in the corners. Sand may be substituted by baby jelly. The water cement proportion used is among 0.4 to 0.45 .

\section{Experimental Methodology}

In this experimental program, the aim is to compare the basic properties of control concrete such as compressive strength and at 7 days, 14 days, and 28 days with the properties of concrete made using asbestos fibre at every percent of fibre content. For this, the experimental program is divided into seven groups. The 1st group is the control concrete with $0 \%$ of asbestos fibre, 2nd group consists of $0.33 \%$ of asbestos fibre by volume of concrete, 3rd group consists of $0.66 \%$ of Asbestos fibre by volume of concrete, 4 th group consists of $1.00 \%$ of Asbestos fibre by volume of concrete, 5th group consists of $1.33 \%$ of Asbestos fibre by volume of concrete, 6th group consists of $1.66 \%$ of Asbestos fibre by volume of concrete, And the 7th group consists of $2.00 \%$ of Asbestos fibre by volume of concrete. The mix design was carried out for M-30 Grade of concrete conferring to the guidelines provided by IS: 10262-2009 "Code of Concrete Mix proportioning" and IS: 456-2000 "Code of practice for Plain and Reinforced Concrete".

Table-1 Mix Proportions for M 30 grade Concrete

\begin{tabular}{|c|c|c|c|}
\hline S. N. & Materials & Quantity $\left.\mathbf{( k g} / \mathbf{m}^{\mathbf{3}}\right)$ & Proportions \\
\hline 1 & Cement & 398.7013 & 1 \\
\hline 2 & Water & 179.4156 & 0.45 \\
\hline 3 & Fine Aggregate & 670.029 & 1.6805 \\
\hline 4 & Coarse Aggregate & 1175.2471 & 2.9476 \\
\hline 5 & Super-plasticizer & 3.987 & 0.01 \\
\hline
\end{tabular}

Table-2. As per Indian Standard code the size of cubes and beams used during this experiments are given

\begin{tabular}{|c|c|c|c|}
\hline Sl. No. & Type of Strength Test & Relevant IS Code & Specimen Details \\
\hline 1 & Compressive Strength & IS 516-1959 & $150 \times 150 \times 150 \mathrm{~mm}$ Cube \\
\hline 2 & Flexural Strength & IS 516-1959 & $700 \times 150 \times 150 \mathrm{~mm}$ Beam \\
\hline
\end{tabular}

The concrete mix conferring to the guidelines provided by IS: 10262-2009 is prepairedthis concrete is poured in the mould and tempered properly so as not to have any voids. After 24 hours these moulds are removed and test specimens are put in water for curing. The top surface of these specimen should be made even and smooth. This is done by putting concrete paste and spreading smoothly on whole area of specimen. These specimens are tested by compression testing machine (for cube) and Flexural test machine (for beam)after 7 days curing, 14 days curing or 28 days curing. Load should be applied gradually at the rate of $140 \mathrm{~kg} / \mathrm{cm}^{2}$ per minute (for cube test) and $7 \mathrm{~kg} / \mathrm{cm}^{2}$ per minute (for flexural strength test) till the Specimens fails. Thus compressive strength and flexural strength of concrete is calculated.

\subsection{Compressive strength test results.}

\section{Test Results}

The property like Compressive Strength at hardened state of AFRC at the age of 7, 14 and 28 days evaluated by using automatic compressive strength testing machine by applying the load at the side faces of cube as they were cast in the mould. Three cubes for each percent at different test age have tested to determine the average compressive strength for, AFRC. 
Table-3 Compressive Strength Test Results of AFRC at Age of 7 days

\begin{tabular}{|c|c|c|}
\hline Sl. No. & $\begin{array}{c}\text { \%) Addition of Asbestos Fibre by Volume } \\
\text { of Concrete }\end{array}$ & $\begin{array}{c}\text { Average Compressive Strength at 7 days } \\
\text { (MPa) }\end{array}$ \\
\hline 1 & 0.00 & 27.78 \\
\hline 2 & 0.33 & 29.93 \\
\hline 3 & 0.66 & 29.71 \\
\hline 4 & 1.00 & 28.59 \\
\hline 5 & 1.33 & 26.45 \\
\hline 6 & 1.66 & 25.63 \\
\hline 7 & 2.00 & 22.08 \\
\hline
\end{tabular}

Table-4 Compressive Strength Test Results of AFRC at Age of 14 days

\begin{tabular}{|c|c|c|}
\hline Sl. No. & $\begin{array}{c}\text { (\%) Addition of Asbestos Fibre by } \\
\text { Volume of Concrete }\end{array}$ & $\begin{array}{c}\text { Average Compressive Strength at 14 } \\
\text { days (MPa) }\end{array}$ \\
\hline 1 & 0.00 & 27.78 \\
\hline 2 & 0.33 & 29.93 \\
\hline 3 & 0.66 & 29.71 \\
\hline 4 & 1.00 & 28.59 \\
\hline 5 & 1.33 & 26.45 \\
\hline 6 & 1.66 & 25.63 \\
\hline 7 & 2.00 & 22.08 \\
\hline
\end{tabular}

Table-5 Compressive Strength Test Results of AFRC at Age of 28 days

\begin{tabular}{|c|c|c|}
\hline Sl. No. & $\begin{array}{c}\text { (\%) Addition of Asbestos Fibre by } \\
\text { Volume of Concrete }\end{array}$ & $\begin{array}{c}\text { Average Compressive Strength at 28 } \\
\text { days (MPa) }\end{array}$ \\
\hline 1 & 0.00 & 38.46 \\
\hline 2 & 0.33 & 41.34 \\
\hline 3 & 0.66 & 40.89 \\
\hline 4 & 1.00 & 38.74 \\
\hline 5 & 1.33 & 35.48 \\
\hline 6 & 1.66 & 34.23 \\
\hline 7 & 2.00 & 30.37 \\
\hline
\end{tabular}

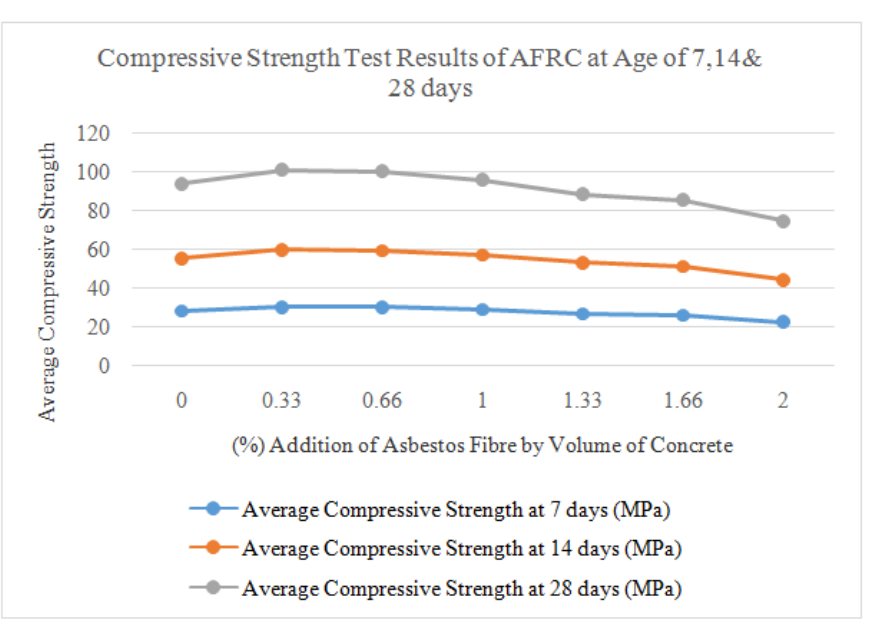

from the results of compressive strength of AFRC at 7, 14 , and 28 days, it has found that maximum compressive strength is obtained at $0.33 \%$ addition of asbestos fibre as $41.34 \mathrm{MPa}$ at 28 days. However beyond $0.33 \%$ up to $2.0 \%$ addition of asbestos fibre decreased the compressive strength at any age of AFRC.

\subsection{Flexural Strength Test Results.}

The Flexural Strength test at different test age of 7, 14 and 28 days have evaluated by using a manual flexural strength-testing machine. Three beams for each percent have tested to determine the average flexural strength under third point loading for AFRC. The results of flexural strength after testing are mentioned below in tabular form and for further analysis and studies graph is formulated. 
Table-6 Flexural Strength Test Results of AFRC at Age of 7 days

\begin{tabular}{|c|c|c|}
\hline Sl. No. & $\begin{array}{c}\text { (\%) Addition of Asbestos Fibre by Volume } \\
\text { of Concrete }\end{array}$ & $\begin{array}{c}\text { Average Flexural Strength at 7 days } \\
\text { (MPa) }\end{array}$ \\
\hline 1 & 0.00 & 3.87 \\
\hline 2 & 0.33 & 4.57 \\
\hline 3 & 0.66 & 4.69 \\
\hline 4 & 1.00 & 4.16 \\
\hline 5 & 1.33 & 3.48 \\
\hline 6 & 1.66 & 3.07 \\
\hline 7 & 2.00 & 2.65 \\
\hline
\end{tabular}

Table-7 Flexural Strength Test Results of AFRC at Age of 14 days

\begin{tabular}{|c|c|c|}
\hline Sl. No. & $\begin{array}{c}\text { (\%) Addition of Asbestos Fibre by Volume } \\
\text { of Concrete }\end{array}$ & $\begin{array}{c}\text { Average Flexural Strength at 14 days } \\
(\mathbf{M P a})\end{array}$ \\
\hline 1 & 0.00 & 4.27 \\
\hline 2 & 0.33 & 4.93 \\
\hline 3 & 0.66 & 5.09 \\
\hline 4 & 1.00 & 4.73 \\
\hline 5 & 1.33 & 4.19 \\
\hline 6 & 1.66 & 3.92 \\
\hline 7 & 2.00 & 3.25 \\
\hline
\end{tabular}

Table-8 Flexural Strength Test Results of AFRC at Age of 28 days

\begin{tabular}{|c|c|c|}
\hline Sl. No. & $\begin{array}{c}(\%) \text { Addition of Asbestos Fibre by Volume } \\
\text { of Concrete }\end{array}$ & $\begin{array}{c}\text { Average Flexural Strength at 28 days } \\
\text { (MPa) }\end{array}$ \\
\hline 1 & 0.00 & 5.13 \\
\hline 2 & 0.33 & 5.87 \\
\hline 3 & 0.66 & 6.27 \\
\hline 4 & 1.00 & 5.64 \\
\hline 5 & 1.33 & 5.03 \\
\hline 6 & 1.66 & 4.68 \\
\hline 7 & 2.00 & 3.95 \\
\hline
\end{tabular}

Flexural Strength Test Results of AFRC at Age of 7,14\& 28 days

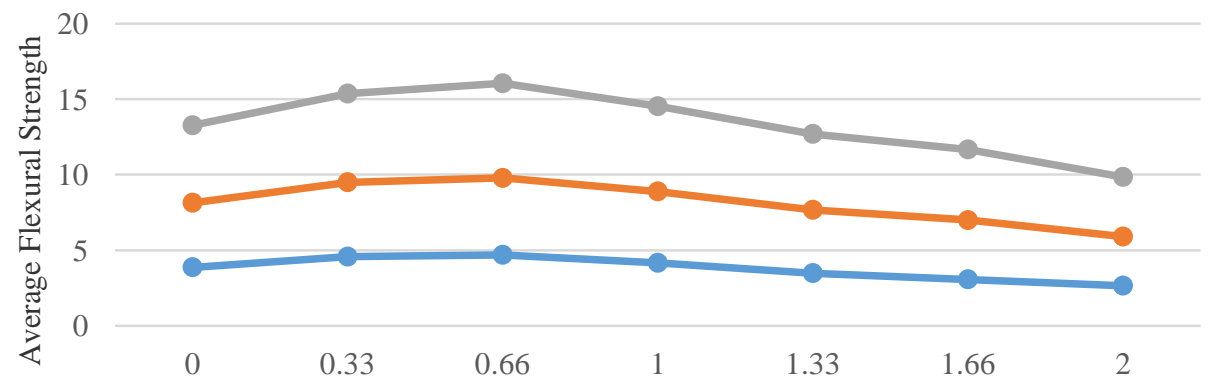

(\%) Addition of Asbestos Fibre by Volume of Concrete

- Average Flexural Strength at 7 days (MPa)

Average Flexural Strength at 14 days (MPa)

- Average Flexural Strength at 28 days $(\mathrm{MPa})$

From the results of flexural strength of AFRC at 7, 14, and 28 days, it has found that maximum flexural strength is obtained at $0.66 \%$ addition of asbestos fibre as $6.27 \mathrm{MPa}$ at 28 days. However, beyond $0.66 \%$ up to $2.0 \%$ addition of asbestos fibre decreased the flexural strength at any age of AFRC. 


\section{Conclusions}

Based on the present experimental studies conducted and the analysis of test results the following conclusions are drawn:

1. Compressive strength and flexural strength of AFRC initially increases with addition of fibre. Further addition of fibre beyond a particular percent, decreases the compressive strength and flexural strength.

2. Flexural strength was increased considerably with fibre reinforcement in case of AFRC.

3. In case of addition of asbestos fibre by volume fraction there is increase in compressive strength at $0.33 \%$ and further addition of asbestos fibre beyond $0.33 \%$ decreases the compressive strength of AFRC.

4. The flexural strength of AFRC at $0.33 \%$ and $0.66 \%$ increases continuously, further addition of asbestos fibre after $0.66 \%$ the flexural strength decreases.

5. In case of AFRC, $0.66 \%$ addition of asbestos fibre, by volume can be taken as the optimum percent for flexural strength and $0.33 \%$ can be taken as optimum percent for compressive strength, which can be used for giving maximum possible flexural strength and compressive strength at any age for Asbestos Fibre Reinforced Concrete.

[1] Jones F. E. (1974), "Weathering Test on Asbestos Cement Roofing Material", Building Research Technical paper No. 29 , H.M.S.O., London.

[2] Jothi D. (2008), "Application of Fibre Reinforcement Concrete Technique in Civil Constructions", African International MultiDisciplinary Journal, Vol-2, pp.157-172.

[3] Majumdar A. J. and Nurse R. W. (1974), “Glass Fibre Reinforcement Cement”, Building Research Establishment current paper, CP79/84, England.

[4] Opoczky L. and Pentek (1975), "Investigation of the Corrosion of Asbestos Fibre in Asbestos Cement Sheets Weathered for Long Term", in A. Neville (ed.) "Fibre Reinforced Cement and Concrete", Proc. RILEM Symp., The Construction Press, England.

[5] Priestley M. J. N, Seible F. and Calvi, G. M. (1996), "Seismic Design and Retrofit of Bridges," New York.

[6] Wafa F. F. (1990), "Properties and Applications of Fiber Reinforced Concrete", JKAU, Engg. Science, Vol. 2, pp. 49-56.

[7] Perumalsamy N. Balaguru and Shah Sarendra P. (1992), "Fiber Reinforced Cement Composites", McGraw Hill International Editions.

Rahul Chaudhary. "Experimental Analysis of Asbestos Fibre Reinforced Concrete Composite." IOSR Journal of Mechanical and Civil Engineering (IOSR-JMCE) 14.4 (2017): 18-22. 